\title{
Como é o chefe ideal? Um estudo sobre a sua representação social em portugueses
}

\author{
Lisete Mónico ${ }^{1}$, Leonor Pais ${ }^{1}$, Inês M. Pratas ${ }^{1}$ \& Nuno R. dos Santos ${ }^{2}$ \\ ${ }^{1}$ Faculdade de Psicologia e de Ciências da Educação da Universidade de Coimbra \\ 2 Universidade de Évora
}

\begin{abstract}
Resumo: Sendo a liderança uma das temáticas que mais atenção tem recebido por parte dos investigadores das Ciências Sociais, o objetivo deste estudo é identificar e interpretar as representações sociais do chefe ideal entre portugueses. Para o efeito, foram inquiridas 2725 pessoas. Recorremos à Técnica de Associação Livre de Palavras para aceder às evocações do chefe ideal. Estas foram classificadas através do Quadro de Quatro Casas em função do seu valor significativo, possibilitando a identificação dos seguintes elementos constituintes do núcleo central: "compreensivo", "respeitador", "líder", "simpático" e "competente". Foi analisada a invariância do núcleo central em função das variáveis sexo, idade e ocupação de um cargo de chefia. Os resultados sugerem alguma aproximação semântica aos modelos de liderança positiva e virtuosa com o que a nossa amostra definiu como sendo o chefe ideal.
\end{abstract}

\section{Palavras-chave: Representações Sociais; Chefe Ideal; Liderança; Líder.}

How is the ideal boss? A study about its social representation in the Portuguese population: The aim of this study is to identify and interpret the social representations of the ideal boss among Portuguese people, based on the fact that leadership is one of the themes that has received most attention from Social Sciences researchers. To this end, 2725 people were surveyed. We used the Free Word Association technique to access the evocations of the ideal boss. The evocations were classified through the Four-Frame Table as a function of their significant value, making it possible to identify the following constituent elements of the central core: "comprehensive", "respectful", "leader", "sympathetic" and "competent". The central nucleus invariance and the variance of the peripheries were analyzed according to the variables gender, age and occupation of a managerial position. The results suggest some similarity between models of positive and virtuous leadership and what our sample defined as the ideal boss.

Keywords: Social Representation; Ideal Boss; Leadership; Leader.

Nos últimos tempos, assistimos a diversos escândalos no mundo dos negócios, na governação dos países, em organizações e noutras instituições (Reed, Vidaver-Cohen, \& Colwell, 2011). Por este motivo, a sociedade tem vivenciado um período de transformação que se caracteriza por um processo de reorganização e reformulação da visão do mundo, dos valores básicos e das estruturas sociais e políticas (Besen, Tecchio, \& Fialho, 2017). O estudo das representações sociais revela-se importante para compreender a relação entre significados sociais mais amplos e o modo como os indivíduos pensam e expressam essas realidades (Daniel, Caetano, Monteiro, \& Amaral, 2016).

No que respeita ao estudo da liderança, até aos anos 80 a eficácia do líder era frequentemente medida em duas dimensões: (1) uma ligada a comportamentos que ajudam a desenvolver relacionamentos positivos entre líder e os demais elementos das respetivas equipas. Esta dimensão, por vezes designada 'consideração', caracteriza-se pela confiança mútua, afabilidade, preocupação com o bem-estar, respeito e relacionamento; e (2) outra ligada à estrutura, que compreende comportamentos de organização das tarefas, distribuição de trabalho, definição das interações funcionais na equipa, estabelecendo canais de comunicação e facilitando a realização de objetivos do grupo (Holtz \& Harold, 2012).

Porém, a partir dessa altura escasseou o interesse pelas questões referidas, facto que se traduziu numa diminuição da literatura sobre elas publicada, devido a várias deficiências metodológicas e conceptuais e à insuficiente utilidade direta na liderança da época (Judge, Piccolo, \& Ilies, 2004). A par disso, este foi um período marcado pelas crises financeiras, políticas e morais que se tornaram predominantes em muitos dos líderes carismáticos, dinâmicos e aparentemente transformativos. Por este motivo, a tónica da investigação passou a incidir sobre a liderança sustentada em valores com uma base

${ }_{1}^{1}$ Morada para correspondência: Lisete Mónico, Faculdade de Psicologia e de Ciências da Educação, Rua do Colégio Novo, $3000-115$ Coimbra, Portugal. E-mail: lisete.monico@fpce.uc.pt 
moral e ética subjacente (Copeland, 2014), e em aspetos que vão para além da eficácia medida pelos resultados. De facto, a crise económica mundial desafiou os investigadores da área das organizações a questionar suposições sobre a estratégia empresarial efetiva e a definir novos modelos de liderança capazes de responder adequadamente às exigências de uma sociedade global essencialmente interdependente (Reed et al., 2011). Considerando que os líderes têm um papel saliente na condução da ação organizacional, foi-lhes dado destaque quer na procura de explicações sobre as causas da crise, quer na procura de soluções preventivas de situações idênticas futuras.

É por este motivo que os investigadores se têm dedicado ao estudo de lideranças virtuosas e positivas, cujo foco está para além dos resultados operacionais imediatos, tendo uma base ética e moral mais ou menos evidente. Muitos modelos têm sido desenvolvidos dentro desta linha de trabalhos, com alguma variação entre eles quanto à sofisticação conceptual e ao suporte empírico. São exemplos a Liderança Espiritual (Mubasher, Salman, Irfan, \& Jabeen, 2017), a Liderança Responsável (Miska \& Mendenhall, 2018), a Liderança Autêntica (Avolio \& Gardner, 2005), a Liderança Ética (Brown, Treviño, \& Harrison, 2005) e a Liderança Servidora (Greenleaf, 1970). A Liderança Empoderadora (Sharma \& Kirkman, 2015), embora tenha um conteúdo menos diretamente vinculado à ética e à virtuosidade, pode ser considerada uma proposta de liderança positiva, cuja tónica está para além dos resultados e acentua o desenvolvimento pessoal de cada um dos colaboradores.

No presente trabalho iremos dar particular atenção à liderança autêntica, à liderança ética, à liderança servidora e à liderança empoderadora enquanto termos de comparação para o estudo das representações sociais do chefe ideal. Tal deve-se ao facto de serem, de entre os modelos de liderança virtuosa, os mais citados, e ao facto de a liderança empoderadora ser definida com base no impacto positivo no empoderamento dos colaboradores. Se, por um lado, os investigadores se têm debruçado sobre o desenvolvimento destes modelos focados na virtuosidade e positividade da liderança - e por isso representando um certo ideal -, por outro, apresenta-se como relevante conhecer o entendimento do cidadão não especialista a respeito daquilo que considera ser um chefe ideal. Por conseguinte, e face ao exposto, o presente estudo pretende contribuir para a identificação, análise e interpretação da representação social do perfil do Chefe Ideal numa amostra de portugueses.

Embora chefe e líder não sejam termos coincidentes, assumimos neste trabalho um significado amplo de liderança, como se observa na tradição de investigação sobre o conceito, que pode incluir tanto o superior imediato de um trabalhador, como o dirigente empresarial ou político. Por essa razão nos reportamos à literatura sobre liderança, e aos modelos virtuosos e positivos que mencionámos, que não se propõem excluir, nas suas análises, qualquer dos níveis de liderança suscetíveis de ser considerados. Efetivamente, na literatura académica a palavra correntemente usada para o estudo do exercício de um cargo de poder e autoridade, no quadro de uma organização, é liderança. Além disso, a nossa escolha da expressão chefe decorre de considerarmos que remete para o superior hierárquico imediato, com quem existirá, em princípio, maior frequência de contacto direto, e por isso a respeito de quem é mais fácil construir uma representação de ideal.

\section{Representações Sociais}

O estudo das representações sociais foi impulsionado por Moscovici, a partir de 1961. 0 autor considera que as representações sociais formam-se no decurso das interações e que diferentes relações comunicacionais fazem emergir diferentes representações. Trata-se, por isso, de um "conjunto de conceitos, proposições e explicações criado na vida quotidiana no decurso da comunicação interindividual" (Moscovici, 1981, p. 181). Abric (2001) define a representação social como "um conjunto organizado e estruturado de informações, crenças, opiniões e atitudes, que constitui um sistema sociocognitivo particular composto por dois subsistemas que interagem: um sistema central e um sistema periférico" (p. 82). Na sua essência, estas definições remetem para um fenómeno que resulta das tentativas humanas de produzir sentido, utilizado para comunicarmos e coordenarmos as nossas ações de forma a podermos viver em comunidade (Vala \& Castro, 2013).

Neste estudo, seguimos a abordagem estrutural das representações sociais, também conhecida por Teoria do Núcleo Central (ou abordagem do núcleo central), proposta em 1976 em Aix-en-Provence por Jean Claude Abric (1976, 1987, 1994a, 1994b). Esta abordagem ilustra a arquitetura interior da representação social, entendendo-a como um conjunto estruturado de crenças, opiniões, informações e atitudes composto por dois subsistemas: o central e o periférico. Recorrendo à técnica de associação livre de palavras, possibilita o acesso aos elementos implícitos ou latentes que seriam perdidos/mascarados nas produções discursivas das pessoas (Abric, 2001).

Segundo Abric (1976, 1987, 1994a, 1994b), toda a representação se social encontra estruturada em torno de um núcleo central, constituído por um ou mais elementos que conferem significado à representação. 0 núcleo central é o elemento crucial da representação, na medida em que, 
simultaneamente, confere significado e organiza a representação, pautando-se pela memória coletiva, refletindo as condições sócio-históricas e os valores do grupo que detém a representação social.

O núcleo central constitui a base comum, consensual e coletivamente partilhada da representação. É estável, coerente e resistente à mudança, sendo pouco sensível ao contexto social e material imediato no qual a representação se manifesta (Sá, 1998). Consiste num ou mais elementos, sempre em número limitado e com ordens de evocação que ocupam as primeiras posições na hierarquia das evocações pela técnica de associação livre de palavras (Abric, 2001). Tradutor de significação, consistência e permanência na representação, o núcleo central desempenha funções essenciais que determinam o significado da representação (fonction génératrice), a sua organização interna (fonction organisatrice) e a sua estabilidade (fonction stabilisatrice) (Abric, 2001).

Já o sistema periférico da representação social tem um carácter mais individualizado, flexível e contextualizado, permitindo o ajustamento a mudanças e adaptação à realidade, bem como modulações pessoais em relação a um núcleo central comum, podendo conduzir, no futuro, à emergência do que poderemos apelidar de representações sociais individualizadas (Abric, 1993, 1994b). Tais representações podem futuramente vir a definir a zona de contraste de uma representação social (Abric, 2003), na medida em que esta integra, na associação livre de palavras, elementos com ordens de evocação recentes na hierarquia das evocações (entenda-se, ocupando as primeiras posições na hierarquia de evocações), embora pouco frequentes, colocando-se em questão a sua representatividade (Abric, 2003; Sá, 1996, 1998). Efetivamente, a zona de contraste é constituída por termos pouco frequentes e com ordens médias de evocação baixas, indicando a possibilidade da existência de uma representação social específica de um grupo de indivíduos. Assim, esta zona encontra-se significativamente mais associada às características idiossincráticas e ao contexto imediato onde as pessoas vivem; desempenha tanto uma função adaptativa (permite o ajustamento da representação à realidade enfrentada pelos indivíduos) quanto defensiva (protege o sistema central da informação suscetível de questionamento) (Rosa, Tafani, Michel, \& Abric, 2011).

Os elementos do sistema periférico “(...) são hierarquizados, ou seja, podem estar mais ou menos próximos dos elementos centrais: próximos do núcleo central, eles desempenham um papel importante na concretização do significado da representação; mais distantes, eles ilustram, explicitam ou justificam este significado" (Abric, 1994b, p.25). O sistema periférico é constituído pelas primeira e segunda periferias da representação social. A primeira periferia integra elementos muito frequentes com ordens de evocação mais finais na hierarquia das evocações (entenda-se, ocupando as últimas posições na hierarquia de evocações); a segunda abarca elementos menos frequentes e igualmente com ordens de evocação mais finais na hierarquia das evocações. Refira-se que o sistema periférico não é um elemento menor da representação; reconhece-se a sua importância, na medida em que associado ao núcleo central, permite a ancoragem do novo ou do estranho na estrutura representacional, constituindo um forte indicador de alterações futuras na representação.

\section{Liderança Autêntica}

$\mathrm{O}$ conceito de autenticidade tem as suas raízes na Filosofia Grega e revela-se nas injunções "conhecer-se a si mesmo" ou "o teu verdadeiro ser" (Walumbwa, Avolio, Gardner, Wernsing, \& Peterson, 2008). Os indivíduos autênticos são pessoas funcionais, que estão livres das expectativas que os outros têm sobre si, podendo, deste modo, fazer melhores escolhas pessoais. São, também, pessoas autorrealizadas, com fortes convicções éticas (Avolio \& Gardner, 2005). A autenticidade pode, então, ser definida como a posse de experiências pessoais, sejam elas pensamentos, emoções, necessidades, desejos, preferências ou crenças, processos capturados pela injunção "conhecer-se a si mesmo" (Harter, 2002).

A liderança autêntica emerge no final do século XX, por duas razões distintas. Por um lado, o (re)surgimento da Psicologia Positiva leva a uma crescente reflexão sobre a liderança, com tónica sobre a autorrealização do líder e dos seus subordinados (Moriano, Molero, \& Mangin, 2011). Por outro, ocorre na evidência da crise económica contemporânea e do comportamento dececionante dos líderes políticos e empresariais, impulsionando a importância dos aspetos éticos e morais da liderança (Miniotaité \& Buciuniené, 2013; Moriano et al., 2011).

A liderança autêntica é um constructo positivo que constitui a base dos modelos positivos de liderança (Avolio \& Gardner, 2005). É definido como um "padrão de comportamento do líder que se baseia e promove tanto as capacidades psicológicas positivas, como um clima ético positivo, com o objetivo de promover uma maior autoconsciência e perspetiva moral, um tratamento mais equilibrado da informação e a transparência das relações com os seus subordinados, promovendo o autodesenvolvimento positivo" (Walumbwa et al., 2008, p. 94). A liderança autêntica engloba quatro componentes principais - Autoconsciência, Transparência Relacional, Perspetiva Moral e Processamento 
Equilibrado - que refletem as perceções empíricas e conceptuais acerca destes líderes (Walumbwa et al., 2008).

A Autoconsciência inclui o conhecimento do self e do seu próprio potencial. É um processo que reflete os valores, identidade, emoções, objetivos, conhecimentos, talentos e capacidades únicas do indivíduo (Gardner, Avolio, Luthans, May, \& Walumbwa, 2005) e inclui uma reavaliação contínua do autoconceito através da exposição e feedback dos outros e a consciência do modo como a sua ação influencia os subordinados (Peus, Wesche, Streicher, Braun, \& Frey, 2011).

A Transparência Relacional consiste na apresentação do self autêntico, e não distorcido, aos outros (Hsiung, 2012). Esta capacidade dos líderes manifesta-se em comportamentos como abertura, partilha de informações e expressão dos seus próprios pensamentos e sentimentos nas relações interpessoais (Peus et al., 2011).

A Perspetiva Moral é uma forma de autorregulação internalizada e integrada, orientada pelas atitudes, valores e padrões morais do líder (Randolph-Seng \& Gardner, 2012). Expressa-se nos processos de tomada de decisão (Avollio \& Gardner, 2005).

O Processamento Equilibrado reflete o reconhecimento de que, embora todos os seres humanos possam ser tendenciosos no seu processamento cognitivo de informação, o equilíbrio vem do reconhecimento explícito de que esses preconceitos são operacionais, ao mesmo tempo que se esforçam por minimizar os seus efeitos na procura da objetividade (Randolph-Seng \& Gardner, 2012). Dito de outro modo, o Processamento Equilibrado refere-se à capacidade do líder analisar objetivamente todos os dados relevantes antes de tomar uma decisão (Hsiung, 2012; Moriano et al., 2011).

Concluímos, assim, que os líderes autênticos se orientam por fortes convicções morais, atuam de acordo com os seus valores e crenças, estão conscientes dos seus pontos fortes e fracos e esforçam-se por entender o modo como a sua ação influencia os outros (Peus et al., 2011). 0 desenvolvimento deste modelo é uma expressão da preocupação, por parte dos investigadores, de proporem uma forma virtuosa de liderança, procurando, portanto, que corresponda de alguma forma a um ideal.

\section{Liderança Ética}

Dadas as crises morais nos âmbitos social, empresarial e político que referimos anteriormente, assistimos à emergência do interesse pelo estudo da ética na liderança (Bedi, Alpaslan, \& Green, 2016). Brown et al. (2005) definiram a liderança ética como a "demonstração de condutas normativamente apropriadas através de ações pessoais e relações interpessoais e da sua promoção com recurso a comunicação two-way, reforço e tomada de decisão. Os líderes éticos agem como modelos de comportamento e utilizam, adequadamente, a recompensa e a punição como modo de estimular as condutas éticas" (p. 120).

O comportamento ético é um elemento-chave comum a várias conceções teóricas vizinhas (e.g., liderança transformacional, autêntica e espiritual). Todavia, nenhuma delas explica completamente o modo como o comportamento ético dos líderes influencia o comportamento ético dos seus subordinados ou mesmo dos diversos stakeholders. Para preencher esta lacuna, Brown e Treviño (2006) recorreram à Teoria da Aprendizagem Social (Bandura, 1977) e à Teoria da Troca Social (Blau, 1964).

A primeira foca os antecedentes e as consequências da liderança ética e defende que os indivíduos aprendem as condutas normativamente apropriadas de duas formas: através da sua própria experiência e da observação dos outros (Bandura, 1986). De facto, segundo a teoria supracitada, uma das formas mais eficazes de influenciar o comportamento humano é observar as ações dos outros, especialmente daqueles que consideramos atraentes quer pelo poder quer pelo status. Por conseguinte, os líderes que demonstram condutas normativamente apropriadas são vistos como modelos legítimos e credíveis a seguir - processo de modelagem (Wolde, Groenendaal, Helsloot, \& Schmidt, 2014).

A segunda propõe que as normas de reciprocidade englobem muitas relações sociais. Dito de outro modo, quando os subordinados percebem um líder como preocupado com o seu bem-estar, sentem-se obrigados a corresponder com o mesmo nível de apoio (Bedi et al., 2016). Assim, os líderes são vistos como honestos, confiáveis, justos e solidários, norteando as atitudes e comportamentos dos liderados, por forma a estruturarem ambientes de trabalho justos (Neves, Jordão, Cunha, Vieira, \& Coimbra, 2016).

Na discussão da liderança ética, são, ainda, consideradas duas dimensões-chave: "gestor moral" e "pessoa moral" (Treviño, Hartman, \& Brown, 2000). Ser um gestor moral é chamar a atenção para as normas e valores éticos na organização e tentar promover o comportamento ético dos subordinados ao estabelecer padrões e expectativas de conduta moral. Ser uma pessoa moral implica que as pessoas pensem no líder como um indivíduo possuidor de certos traços (e.g., respeitador, confiável) e que manifesta comportamentos e decisões orientadas por princípios éticos (Wolde et al., 2014).

Treviño e colaboradores (Brown \& Treviño, 2006; Brown et al., 2005; Treviño et al., 2000) identificaram cinco comportamentos e características fundamentais de um líder ético: (a) integridade - o 
líder ético é honesto e confiável; (b) equidade - o líder ético é transparente e não expressa favoritismo; (c) comunicação de normas éticas - o líder ético encontra formas de explicitar e promover os padrões éticos do grupo; (d) cuidado e preocupação com os outros - o líder ético trata todos os seus subordinados com respeito e dignidade; e, por último, (e) partilha de poder - o líder ético escuta as ideias e preocupações de todos os trabalhadores.

A investigação sobre liderança ética demonstra que o carácter de um líder é importante para promover resultados positivos nas organizações e, particularmente, nos subordinados (Brown et al., 2005). Esses resultados expressam-se em maior confiança, maior comprometimento, menos comportamentos contraproducentes, maior abertura para identificar e denunciar problemas e, ainda, menos sentimentos de intimidação (Schwartz, 2015). A liderança ética é, portanto, tal como a liderança autêntica, um modelo que expressa um certo ideal virtuoso e que, por isso, correspondente ao que os seus criadores identificam como uma forma de liderança ideal.

\section{Liderança Servidora}

O conceito de Liderança Servidora foi desenvolvido por Robert Greenleaf, na década de 70, e os seus pressupostos teóricos assentam nos preceitos do cristianismo e da filosofia, no que concerne a servir o próximo, crescimento pessoal, autoconsciência e identificação, combinados com o conceito de uma visão partilhada (Almeida \& Faro, 2016).

$\mathrm{Na}$ sua essência, este modelo enraíza-se numa abordagem de liderança pela qual os líderes encaram altruisticamente as suas funções como uma oportunidade para servir os indivíduos, a organização e a comunidade onde se inserem, e não como um veículo para alcançar prestígio e poder pessoal (Aij \& Rapsaniotis, 2017; Newman, Schwarz, Cooper, \& Sendjaya, 2015; Parris \& Peachey, 2013). Investem, deste modo, no desenvolvimento de skills dos subordinados para que se tornem futuros líderes servidores (Reed et al., 2011), atuam como modelos e fonte de suporte, envolvem os colaboradores na tomada de decisão. Além disso, enfatizam a importância de servir a comunidade, em geral, na qual estão integrados (Newman et al., 2015) e exibem comportamentos éticos baseados na honestidade, humildade, confiança e serviço (Finley, 2012), melhorando a qualidade de vida organizacional (Spears, 2010).

Spears (2010) apresentou o perfil de um líder servidor, organizado em torno de 10 características. Estas características são: (1) capacidade de ouvir - marcada por um compromisso profundo de ouvir atentamente os subordinados e compreender as suas necessidades; (2) empatia - o líder deve ser empático com os seus subordinados, encarando-os como pessoas, além de empregados, estimulando, assim, o seu desenvolvimento pessoal; (3) capacidade de cuidar dos seus liderados; (4) consciencialização - prende-se com o facto de o líder ser dotado de uma autoconsciência geral para ajudar a compreender as questões éticas e os valores morais, tendo, porém, a capacidade de ver a situação de forma integrada e holística; (5) persuasão - isto é, convencer os seus subordinados sem uso de poder ou do estatuto que possui; (6) conceptualização - o líder é capaz de pensar além das realidades do dia a dia, ou seja, preocupa-se com metas operacionais a longo-prazo; (7) antecipação - respeita à capacidade de prever o resultado provável de uma situação, alcançando, assim, uma melhor compreensão da realidade atual; (8) espírito de serviço - é visto como a obrigação, em primeiro lugar, de atender às necessidades dos outros; (9) compromisso - consideração de que as pessoas têm um valor intrínseco que vai para além daquilo que são como trabalhadores, sendo, por conseguinte, reconhecida a importância da estimulação pessoal, profissional e espiritual dos liderados; e, por último, (10) preocupação com a comunidade - ou seja, a identificação dos meios necessários para construir uma comunidade forte dentro da própria organização. É importante ainda referir os resultados da revisão sistemática da literatura conduzida por Parris e Peachy (2013). Encontraram fortes evidências de que a liderança servidora melhora a confiança dos subordinados, quer nas suas chefias quer na organização; promove o comportamento de cidadania organizacional e a justiça procedimental; fortalece a eficácia da liderança e das equipas; aumenta a colaboração entre membros da equipa; promove o bem-estar, a satisfação, o comprometimento e a criatividade dos colaboradores; e diminui o turnover.

Importa referir que a liderança servidora tem uma componente moral semelhante à liderança autêntica e à liderança ética, porém a diferença entre elas reside no seu foco em todos os stakeholders e na inclusão de comportamentos altruístas e autorreflexivos (Hunter, 2013). Em síntese, o foco do líder servidor reside no compromisso de servir e inspirar os subordinados a alcançarem os objetivos da organização e os seus próprios objetivos. Trata-se de "uma forma de ser" que é intrinsecamente motivada por valores e crenças pessoais (Aij \& Rapsaniotis, 2017). Trata-se, por isso, uma vez mais, de um modelo de liderança correspondente a um certo ideal formulado pelos investigadores. Este modelo e os demais previamente apresentados dão uma panorâmica ampla de ideais de liderança, tal como definidos na investigação. 


\section{Liderança Empoderadora}

Em resposta ao aumento da concorrência económica global, muitas empresas sofreram mudanças estruturais dramáticas. Para melhorar a sua eficiência substituíram a hierarquia tradicional de gestão por equipas de trabalho capacitadas (semiautónomas ou de autogestão). As tarefas que outrora eram desempenhadas por gestores, como direcionar e controlar o trabalho, são agora realizadas por equipas com competências para o efeito. Os gestores foram convidados a assumir um novo conjunto de funções e responsabilidades para liderar essas equipas (Arnold, Arad, Rhoades, \& Drasgow, 2000). Por essa razão, tornou-se imperativo o envolvimento dos líderes em iniciativas de empoderamento que incluíssem também os subordinados (Sharma \& Kirkman, 2015). No seu núcleo, o empoderamento dos trabalhadores envolve uma motivação individual aprimorada no trabalho através da delegação de responsabilidade e autoridade para o nível organizacional mais baixo, onde possam ser tomadas decisões com competência (Amundsen \& Martinsen, 2014).

Com tónica no desenvolvimento da autogestão e das competências de autoliderança dos subordinados, as bases históricas da liderança empoderadora debruçam-se sobre a teoria social cognitiva e a investigação em modificação do comportamento cognitivo. A autogestão comportamental enraíza-se na Psicologia Clínica. Manz e Sims (1980) expandiram as aplicações clínicas para as organizações, definindo a autogestão como um substituto da liderança. A proposição básica da teoria social cognitiva é a da reciprocidade triádica, assente na premissa de que os indivíduos influenciam o seu ambiente através do seu comportamento e ambos (ambiente e comportamento) influenciam, por seu turno, o indivíduo (Pearce \& Sims, 2002).

Caracterizada pela facilitação e apoio à autonomia, a liderança empoderadora pauta-se, assim, por conferir influência em detrimento de influenciar como acontece noutros tipos de liderança (e.g., diretiva, transacional ou transformacional; Amundsen \& Martinsen, 2014).

Segundo os referidos autores, a liderança supracitada organiza-se em torno de 5 dimensões: (1) liderar pelo exemplo - refere-se a um conjunto de comportamentos que evidenciam o comprometimento do líder com o trabalho dos subordinados e com o seu próprio trabalho; (2) coaching - respeita a comportamentos que orientam os colaboradores e os ajudam a serem autónomos; (3) tomada de decisão partilhada - isto é, abertura do líder à contribuição e participação dos subordinados na tomada de decisão; (4) divulgação de informações sobre a organização (e.g., missão, informações sobre novos desenvolvimentos na política organizacional, etc.); e, por último, (5) preocupação com o bem-estar dos subordinados e disponibilidade para ouvir as suas preocupações (Amundsen \& Martinsen, 2014).

Em suma, a liderança empoderadora é definida como "comportamentos de liderança que consistem em delegar autoridade aos subordinados, promovendo não só as suas decisões autónomas e a partilha de ideias, mas também a recetividade às suas sugestões e opiniões" (Lorinkova, Pearsall, \& Sims, 2013, p. 573). Isto deve ser feito dentro dos limites dos objetivos e estratégias organizacionais (Amundsen \& Martinsen, 2014). Este modelo expressa também, como os anteriores, uma certa forma ideal de exercício da liderança que será relevante utilizar, de forma comparativa, na análise daquilo que corresponda ao ideal dos cidadãos não especialistas quanto ao modo de exercer cargos de gestão, chefia, liderança e direção.

\section{MÉTODO}

A abordagem metodológica utilizada no presente estudo baseia-se na Teoria das Representações Sociais, na sua abordagem estrutural, como nos é apresentada por Abric $(1976,1987,1994 a, 1994 b) .0$ método das evocações livres, por nós utilizado, possibilita a apreensão de projeções mentais de forma descontraída e espontânea, e proporcionando o acesso ao conteúdo semântico preexistente de forma rápida e objetiva (Dany, Urdapilleta, \& Monaco, 2014). 0 recurso a este método possibilita analisar o conteúdo e a sua organização, por forma a delimitar o núcleo central e os elementos periféricos da representação (Oliveira, Marques, Gomes, Teixeira, \& Amaral, 2005).

\section{Participantes}

A amostragem utilizada neste estudo é não probabilística intencional, direcionada para a heterogeneidade ou diversidade (Trochim, Donnelly, \& Arora, 2016). A amostra foi recolhida por uma equipa de investigadores de norte a sul de Portugal Continental e Ilhas, sendo composta por 2725 participantes portugueses dos quais 1713 pertencem ao sexo feminino e 1008 ao sexo masculino $(n=4$ não-respostas). As idades variam entre um mínimo de 16 e um máximo de 90 anos $(M=35$ anos; $D P=$ 14.79), tendo 1494 participantes idades compreendidas entre 17 e 27 anos (Millennials, classificação de Suh, 2015), 761 entre 38 e 52 anos (X generation), 325 entre 53 e 72 anos (Baby boomer generation), 113 entre 28 e 37 anos e 32 acima de anos 72 anos (Silent generation). A maioria dos respondentes $(n=1245)$ frequenta o Ensino Superior, seguindo-se o Ensino Secundário $(n=1069$ participantes $)$ e o Ensino Básico 
( $n=387)$; não responderam ao nível de escolaridade 24 participantes. Em termos de situação profissional, 1025 são efetivos, 575 possuem um contrato a termo, 196 são prestadores de serviço (recibos verdes), 120 encontram-se atualmente desempregados, 98 estão reformados/aposentados e 694 são estudantes (17 não-respostas). No que concerne ao exercício de um cargo de chefia, apenas 518 (19.0\%) respondentes o exercem.

\section{Instrumentos}

No instrumento de recolha de dados recorreu-se ao método de evocação livre de palavras, a partir do termo indutor "Chefe Ideal". Foi pedido aos inquiridos que respondessem da forma mais espontânea possível ao enunciado "Por favor, comece por escrever no quadro abaixo as cinco primeiras palavras ou expressões breves que lhe vêm imediatamente à mente ao ler o termo "Chefe Ideal", respeitando a ordem com que estas lhe vão surgindo na mente". Seguia-se, então, um quadro com cinco linhas. Em cada linha, o respondente era convidado a escrever, em formato de resposta aberta, a palavra/expressão-breve que lhe surgia imediatamente na sua mente. Por último, os inquiridos respondiam a um conjunto de questões de natureza sociodemográfica (cf. variáveis indicadas na caracterização da amostra).

\section{Procedimento}

Foram assegurados todos os cuidados para garantir o anonimato dos participantes e a confidencialidade dos dados, tendo-se tido em conta todos os requisitos formais e éticos. 0 processo de recolha de dados foi realizado com a ajuda de uma equipa de estudantes de Mestrado em Psicologia de uma universidade pública portuguesa. Estes estudantes integravam um projeto de investigação sobre representações sociais, no âmbito do qual o questionário da presente investigação foi administrado, tendo sido devidamente instruídos. Para o efeito, após a participação na sessão de esclarecimento sobre a investigação e os procedimentos formais e éticos, os alunos preenchiam um termo de responsabilidade e, aquando da administração dos questionários, solicitavam aos respondentes a assinatura de um consentimento informado. Cada participante poderia recolher até ao limite máximo de 10 questionários, tendo para o efeito de administrá-los a cidadãos de nacionalidade portuguesa de ambos os sexos e com idades a partir dos 16 anos (critério de inclusão correspondente à idade legal para trabalhar em Portugal), trabalhadores no ativo, estudantes, desempregados e reformados/aposentados. Os estudantes eram instruídos para criarem condições logísticas adequadas à administração dos questionários (espaço físico reservado que minimizasse a possibilidade de interrupções), solicitando aos respondentes que silenciassem o telemóvel e se concentrassem ao máximo na tarefa, que se previa ter a duração de quatro a oito minutos. Foi ainda registado o endereço eletrónico dos respondentes que indicaram pretender receber uma síntese dos resultados obtidos.

\section{Procedimento de análise de dados}

Os dados foram analisados através do software EVOC (Vergès, 2002). Efetuaram-se as seguintes tarefas prévias: (1) digitação das palavras/expressões breves no programa excel, para posterior upload no programa EVOC (Vergès, 2002); (2) revisão de todo o corpus lexicográfico, com eliminação dos acentos das palavras e inserção do hífen nas expressões compostas por mais do que uma palavra (ex., espirito-de-equipa); (3) revisão do corpus lexicográfico e padronização lexical para efeitos de homogeneização, designadamente a harmonização singular/plural (todas as palavras evocadas no plural foram transpostas para o singular), minúscula/maiúscula (todas as palavras em letra minúscula) e masculino/feminino (todas as palavras no masculino); (4) revisão do corpus lexicográfico com harmonização e redução dos termos ao contexto do verbo ou substantivo; e (5) revisão do corpus lexicográfico com padronização semântica tendo por base o sentido e mantendo a mesma grafia nas palavras sinónimas, de modo a que termos sinónimos pudessem surgir da mesma forma (uma única expressão) ao longo de todo o corpus.

O software EVOC é constituído por um conjunto de 16 programas, embora na presente investigação tenha sido apenas necessário utilizar o Lexique, o Trievoc, o Rangmot e o Rangfrq. Trabalhando de forma articulada, estes programas servem de base à construção da matriz de quatro casas (quatro quadrantes), que permitirá identificar o provável núcleo central, a zona de contraste, bem como a primeira e segunda periferias da representação social do chefe ideal.

Através das palavras/expressões breves evocadas pelos participantes, o software calcula um índice de frequência ( $n$ - número de vezes que a palavra/expressão foi referida) e outro de posição para cada termo evocado (desde 1 - termo evocado em primeiro lugar; até à ordem de evocação 5 - termo evocado em último lugar). 0 cruzamento da informação desses dois índices resulta numa matriz de Quatro Casas ou Quatro quadrantes (Abric, 1993, 1994a, 1994b), possibilitando a identificação dos prováveis elementos do núcleo central, zona de contraste e primeira e segunda periferias (ver Tabela 1). 
No quadrante superior esquerdo da matriz de Quatro Casas estão representados os termos que compõem o núcleo central (termos mais frequentes e com ordens de evocação mais baixas, ou seja, referidos nas primeiras posições - ex, 1.ำ e 2..$^{\circ}$ lugares). No quadrante inferior situam-se os termos que representam a zona de contraste (termos pouco frequentes, mas com ordens de evocação igualmente baixas). No quadrante superior direito encontram-se os termos que constituem a primeira periferia (termos mais frequentes e com ordens de evocação mais altas, ou seja, referidos nas últimas posições ex, 4. o e 5. o lugares). Por último, no quadrante inferior direito situam-se os termos constituintes da segunda periferia (termos menos frequentes e com ordens de evocação mais altas), correspondente ao quadrante mais flexível e externo da representação social.

Dado que em ambos os quadrantes superiores da matriz de Quatro Casas se situam os termos evocados com maior frequência, o software sugere um primeiro ponto de corte, atendendo à frequência das evocações. Esse ponto de corte é designado por frequência intermediária e pode ser alterado para um número superior ou inferior, pelo investigador. No presente artigo, o valor decidido para o referido ponte de corte foi de $n=100$. Este valor resultou de uma análise conjugada entre a sugestão do software e a frequência que o investigador considerou que melhor distingue, na presente amostra, entre um termo muito evocado (que irá constituir o núcleo central ou a primeira periferia da representação social, em função da ordem média de evocação de cada termo) e um termo pouco evocado (que irá integrar a zona de contraste ou a segunda preferiria, em função da ordem média de evocação de cada termo).

Com base na ordem média das evocações, o software EVOC sugere um segundo ponto de corte, situado entre 1 (termo evocado em primeiro lugar) e 5 (termo evocado em último lugar). Cabe ao investigador aferir o valor deste segundo ponto de corte, de forma a encontrar o valor que se revela mais distintivo entre os termos que constituirão o núcleo central/zona de contraste e os termos periféricos (primeira e segundas periferias). No caso da presente investigação, a ordem média de evocação (OME) mais indicada para este ponto de corte foi de $\mathrm{OME}=2.70$, valor abaixo do qual os termos são considerados centrais (caso possuam frequências a partir de $n=100$ ) ou pertencentes à zona de contraste (caso possuam frequências inferiores a $n=100$ ). Os termos cujo cálculo da OME foi igual ou superior a 2.70 integram a primeira periferia (caso possuam frequências superiores 100) ou a segunda periferia (caso possuam frequências inferiores a 100).

\section{RESULTADOS}

No total, os 2725 participantes evocaram 13436 palavras (obtivemos 189 não-respostas, devido a alguns participantes terem indicado um número inferior a cinco palavras/expressões breves, embora não igual a zero). Deste total, 547 eram palavras diferentes. A frequência de palavras variou entre $n=1$ (palavra referida por apenas um participante) e $n=998$ evocações da mesma palavra, verificando-se que a palavra mais evocada representou $7.4 \%$ do corpus lexicográfico.

No primeiro quadrante (ver Tabela 1), correspondente ao núcleo central (palavras mais frequentes e com ordens médias de evocação mais baixas), surgiram as seguintes cinco palavras evocadas com frequências que variaram entre $n=243$ e $n=998$ participantes: "compreensivo" ( $n=998$ participantes; OME = 2.35); "respeitador" $(n=843$; OME = 2.42); "líder" $(n=753$; OME = 2.41); "simpático" $(n=358$; $\mathrm{OME}=2.56)$; e "competente" $(n=243 ; \mathrm{OME}=2.66)$. No referente às frequências $(n)$, o ponto de corte definido pelo software EVOC foi de $n=100$ termos, tendo sido calculado a partir das frequências dos termos evocados; palavras ou expressões breves referidas no mínimo 100 vezes são consideradas no grupo das mais frequentes, integrando ora o núcleo central ora a primeira periferia, em função da ordem média de evocações. Relativamente à ordem média de evocações (OME), o software EVOC estabeleceu como ponto de corte o valor de $\mathrm{OME}=2.70$ (numa escala situada de 1 - correspondente às palavras evocadas em primeiro lugar; a 5 - correspondente às palavras evocadas em 5.o lugar, ou seja, último lugar), possibilitando a ordenação dos termos no núcleo central ou na zona de contraste (termos com OMEs < 2.70). Na zona de contraste constaram oito termos, evocados com uma frequência oscilante entre $n=11$ e $n=46$ : "bondoso" ( $n=46 ;$ OME = 2.52); "não-existe" $(n=37 ; \mathrm{OME}=2.00)$; "diálogo" $(n=19 ; \mathrm{OME}$ = 2.32); "chato" ( $n=16 ; \mathrm{OME}=2.69)$; "democrático" ( $n=13$; OME = 2.62); "mentor" $(n=13 ; \mathrm{OME}=2.15)$; "personalidade" $(n=11 ;$ OME = 2.55); e "ordem" ( $n=11 ; 0 M E=2.18)$. Assim, para um pequeno segmento da amostra, a representação social do Chefe Ideal caracteriza-se por estes termos.

Relativamente à primeira periferia (palavras mais frequentes e com ordens médias de evocação mais elevadas, ou seja, evocadas em 3.ํ, 4.o ou 5. o lugar), verificaram-se 28 termos evocados com frequências que oscilaram entre $n=100$ e $n=570$. Os termos "justo" ( $n=570$; OME = 2.84), "amigo" ( $n=$ 447 ; OME $=3.01)$ e "responsável" ( $n=400$; OME $=2.98)$ foram os três termos mais frequentes, com ordens médias de evocação superiores a 2.70 .

Por último, a segunda periferia (palavras com baixa frequência e elevada ordem média de evocação) constituiu-se por 99 termos com frequências que variaram entre $n=10$ e $n=98$ termos 
evocados. Alguns dos seus termos com OME superiores a 2.70 foram: "tolerante" ( $n=98$; OME $=2.84$ ), "espírito-de-equipa" ( $n=91$; OME = 3.41) e "autoritário" $(n=87 ; \mathrm{OME}=2.99)$. A totalidade dos termos periféricos pode ser verificada na Tabela 1 .

Tabela 1. Núcleo Central, Zona de Contraste, Primeira Periferia e Segunda Periferia para a amostra global: frequências (n) e ordens médias de evocação (OME)

\begin{tabular}{|c|c|c|c|c|c|c|}
\hline$f \min .10$ & OME $<2.70$ & & & OME $\geq 2.70$ & & \\
\hline $\begin{array}{l}\text { Freq. } \\
\text { inter. }\end{array}$ & $\begin{array}{l}\text { Núcleo Central } \\
\text { Termo Evocado }\end{array}$ & $\mathbf{n}$ & OME & $\begin{array}{l}\text { Primeira Periferia } \\
\text { Termo Evocado }\end{array}$ & $\mathbf{n}$ & OME \\
\hline \multirow[t]{29}{*}{$\mathrm{n} \geq \mathbf{1 0 0}$} & compreensivo & 998 & 2.35 & justo & 570 & 2.84 \\
\hline & respeitador & 843 & 2.42 & amigo & 447 & 3.01 \\
\hline & líder & 753 & 2.41 & responsável & 400 & 2.98 \\
\hline & simpático & 358 & 2.56 & motivador & 383 & 3.14 \\
\hline & competente & 243 & 2.66 & organizado & 318 & 3.02 \\
\hline & & & & honesto & 278 & 3.10 \\
\hline & & & & exemplo & 266 & 3.09 \\
\hline & & & & trabalhador & 251 & 3.34 \\
\hline & & & & exigente & 225 & 3.14 \\
\hline & & & & imparcial & 225 & 3.27 \\
\hline & & & & comunicativo & 222 & 3.01 \\
\hline & & & & saber-ouvir & 212 & 2.84 \\
\hline & & & & acessível & 165 & 2.86 \\
\hline & & & & confiança & 156 & 3.04 \\
\hline & & & & humano & 150 & 3.08 \\
\hline & & & & presente & 138 & 3.03 \\
\hline & & & & flexível & 133 & 2.88 \\
\hline & & & & ajuda & 131 & 3.01 \\
\hline & & & & inteligente & 129 & 3.41 \\
\hline & & & & profissional & 126 & 3.16 \\
\hline & & & & empenhado & 121 & 3.43 \\
\hline & & & & educado & 115 & 2.79 \\
\hline & & & & humilde & 114 & 3.04 \\
\hline & & & & assertivo & 112 & 2.92 \\
\hline & & & & colaborador & 104 & 2.87 \\
\hline & & & & cooperante & 103 & 3.05 \\
\hline & & & & dinâmico & 100 & 3.34 \\
\hline & & & & empático & 100 & 3.19 \\
\hline & Zona de Contraste & $\mathbf{n}$ & OME & Segunda Periferia & $\mathbf{n}$ & OME \\
\hline \multirow[t]{18}{*}{$\mathrm{n}<100$} & bondoso & 46 & 2.52 & tolerante & 98 & 2.84 \\
\hline & não-existe & 37 & 2.00 & esprito-de-equipa & 91 & 3.41 \\
\hline & diálogo & 19 & 2.32 & autoritário & 87 & 2.99 \\
\hline & chato & 16 & 2.69 & disponível & 76 & 3.05 \\
\hline & democrático & 13 & 2.62 & reconhecedor & 76 & 3.62 \\
\hline & mentor & 13 & 2.15 & orientador & 71 & 3.04 \\
\hline & ordem & 11 & 2.18 & preocupado & 70 & 3.47 \\
\hline & personalidade & 11 & 2.55 & rigoroso & 65 & 3.06 \\
\hline & & & & atento & 64 & 3.20 \\
\hline & & & & correto & 63 & 3.41 \\
\hline & & & & leal & 62 & 3.11 \\
\hline & & & & valoriza-o-trabalhador & 60 & 3.32 \\
\hline & & & & persistente & 58 & 3.55 \\
\hline & & & & cumpridor & 56 & 3.66 \\
\hline & & & & gestor & 56 & 3.11 \\
\hline & & & & ensinar & 55 & 3.29 \\
\hline & & & & tranquilo & 55 & 2.98 \\
\hline & & & & bem-disposto & 53 & 3.06 \\
\hline
\end{tabular}


Tabela 1. (Continuação) Núcleo Central, Zona de Contraste, Primeira Periferia e Segunda Periferia para a amostra global: frequências (n) e ordens médias de evocação (OME)

\begin{tabular}{|c|c|c|c|c|}
\hline Zona de Contraste & n $\quad$ OME & Segunda Periferia & $\bar{n}$ & OME \\
\hline & & saber-mandar & 53 & 2.72 \\
\hline & & delegar & 52 & 2.92 \\
\hline & & formação & 51 & 3.45 \\
\hline & & aberto-a-opiniões & 50 & 3.30 \\
\hline & & boa-relação & 50 & 3.00 \\
\hline & & coordenador & 49 & 2.86 \\
\hline & & integro & 49 & 3.33 \\
\hline & & empreendedor & 48 & 3.27 \\
\hline & & tomada-de-decisão & 48 & 2.96 \\
\hline & & eficiente & 47 & 3.02 \\
\hline & & informado & 47 & 2.92 \\
\hline & & atencioso & 45 & 2.84 \\
\hline & & pontual & 45 & 3.73 \\
\hline & & proativo & 45 & 3.49 \\
\hline & & ambicioso & 44 & 3.61 \\
\hline & & criativo & 44 & 3.84 \\
\hline & & ético & 42 & 3.33 \\
\hline & & coerente & 40 & 3.25 \\
\hline & & pagamentos-em-dia & 40 & 3.05 \\
\hline & & confiante & 37 & 3.49 \\
\hline & & inovador & 37 & 3.70 \\
\hline & & conhecimento & 36 & 3.11 \\
\hline & & divertido & 35 & 3.66 \\
\hline & & positivo & 35 & 3.46 \\
\hline & & solidário & 34 & 3.06 \\
\hline & & boa-apresentação & 32 & 2.81 \\
\hline & & chefe & 32 & 3.13 \\
\hline & & carismático & 30 & 3.50 \\
\hline & & cordial & 29 & 3.45 \\
\hline & & foco-nos-objetivos & 29 & 3.35 \\
\hline & & metódico & 29 & 3.49 \\
\hline & & direto & 28 & 2.86 \\
\hline & & visionário & 28 & 4.04 \\
\hline & & afável & 27 & 3.33 \\
\hline & & bom-ambiente & 27 & 3.89 \\
\hline & & defensor & 27 & 3.63 \\
\hline & & interessado & 27 & 3.26 \\
\hline & & pagar-bem & 27 & 3.15 \\
\hline & & ponderado & 27 & 3.30 \\
\hline & & prestável & 27 & 3.19 \\
\hline & & experiente & 26 & 3.69 \\
\hline & & objetivo & 25 & 3.16 \\
\hline & & paciente & 25 & 3.36 \\
\hline & & sensato & 25 & 3.28 \\
\hline & & capaz & 24 & 3.50 \\
\hline & & arrogante & 23 & 3.87 \\
\hline & & capacidade-critica & 22 & 3.50 \\
\hline & & humor & 22 & 2.91 \\
\hline & & sério & 22 & 3.41 \\
\hline & & elo & 21 & 3.10 \\
\hline & & feedback & 21 & 3.29 \\
\hline & & gestão-de-conflitos & 21 & 3.57 \\
\hline
\end{tabular}


Tabela 1. (Continuação) Núcleo Central, Zona de Contraste, Primeira Periferia e Segunda Periferia para a amostra global: frequências (n) e ordens médias de evocação (OME)

\begin{tabular}{|c|c|c|c|c|}
\hline Zona de Contraste & OME & Segunda Periferia & $\mathbf{n}$ & OME \\
\hline & & partilha & 20 & 3.65 \\
\hline & & prático & 20 & 3.40 \\
\hline & & sociável & 19 & 3.58 \\
\hline & & alegre & 18 & 3.50 \\
\hline & & autónomo & 18 & 2.83 \\
\hline & & liberal & 18 & 3.11 \\
\hline & & motivado & 18 & 3.44 \\
\hline & & transparente & 17 & 3.77 \\
\hline & & compensador & 16 & 3.62 \\
\hline & & generoso & 16 & 3.56 \\
\hline & & resolve-problemas & 16 & 3.81 \\
\hline & & superior & 16 & 3.69 \\
\hline & & liberdade & 15 & 3.00 \\
\hline & & caráter & 14 & 3.00 \\
\hline & & controlador & 14 & 3.07 \\
\hline & & mente-aberta & 14 & 3.86 \\
\hline & & esclarecedor & 13 & 3.07 \\
\hline & & observador & 13 & 2.92 \\
\hline & & sensível & 13 & 3.08 \\
\hline & & sucesso & 13 & 3.30 \\
\hline & & altruísta & 12 & 3.92 \\
\hline & & assíduo & 12 & 3.42 \\
\hline & & perspicaz & 12 & 3.92 \\
\hline & & raro & 12 & 3.08 \\
\hline & & recetivo & 12 & 3.83 \\
\hline & & suporte & 11 & 3.09 \\
\hline & & comprometido & 10 & 3.20 \\
\hline & & otimista & 10 & 3.80 \\
\hline & & perfecionista & 10 & 4.10 \\
\hline
\end{tabular}

Influência do sexo, idade e ocupação de um cargo de chefia na representação social do chefe ideal No presente estudo realizámos ainda a análise da influência das variáveis sociodemográficas relativas ao sexo, idade e à ocupação de um cargo de chefia na representação social do chefe ideal. Apresentamos, de seguida, os resultados referentes ao núcleo central das representações, analisadas em função destas variáveis sociodemográficas.

Os resultados referentes aos participantes do sexo feminino apresentam um núcleo central (OME < 2.70) constituído pelos seguintes cinco termos evocados com frequências que variaram entre $n=141$ e $n$ $=660$ (ponto de corte de $n=90$ participantes, frequência sugerida pelo programa EVOC, acima da qual as palavras com ordens médias de evocação mais baixas são mais frequentes e, por isso, pertencentes ao núcleo central): "compreensivo" ( $n=660 ; \mathrm{OME}=2.27)$; "respeitador" $(n=541 ; \mathrm{OME}=2.42)$; "líder" $(n=$ 474; OME = 2.48); "simpático" ( $n=243 ; \mathrm{OME}=2.51)$; e "competente" $(n=141 ; \mathrm{OME}=2.59)$. Por outro lado, os referentes aos participantes do sexo masculino exibem um núcleo central (OME < 2.70) constituído por quatro termos evocados com frequências que variaram entre $n=113$ e $n=335$ (ponto de corte de $n=80)$ : "compreensivo" $(n=335$; OME $=2.48)$; "respeitador" $(n=300$; OME $=2.41)$; "líder" $(n=$ 277; OME = 2.28); e "simpático" ( $n=113$; OME = 2.64).

A variável Idade foi organizada em categorias com base na classificação geracional de Suh (2015): (1) Silent Generation (anos de nascimento: 1928-1945); (2) Baby Boomer (1946-1964); (3) X Generation (1965-1980); (4) Millennials (1981 - 2001). Com esta categorização pretendemos verificar se existem diferenças significativas nas perceções das diferentes gerações.

0 núcleo central $(\mathrm{OME}<2.60)$ da Silent Generation é composto por dois termos evocados (ponto de corte de $n=5)$ : "compreensivo" ( $n=10$; OME = 2.30) e "respeitador" $(n=6$; OME = 2.17).

A geração Baby Boomer apresentou um núcleo central (OME < 2.60) constituído por quatro termos evocados com frequências que variaram entre $n=35$ e $n=87$ (ponto de corte de $n=35$ ): "respeitador" ( $n$ 
= 87; OME = 2.59); "líder" ( $n=79 ; \mathrm{OME}=2.24)$; “competente" $(n=42 ; \mathrm{OME}=2.50)$; e "simpático" $(n=35 ;$ $\mathrm{OME}=2.46)$.

Relativamente à $X$ Generation, o respetivo núcleo central (OME < 2.60) organizou-se em torno de quatro termos evocados com frequências que oscilaram entre $n=83$ e $n=230$ (ponto de corte de $n=70$ ): "compreensivo" ( $n=230 ;$ OME = 2.30); "respeitador" $(n=226$; OME = 2.44); "líder" $(n=214 ; 0 M E=$ 2.40); e "competente" ( $n=83$; OME = 2.57).

Por fim, o núcleo central (OME < 2.60) da geração Millennials integrou quatro termos evocados com frequências compreendidas entre $n=224$ e $n=619$ (ponto de corte $n=90$ ). Os seus termos mais frequentes foram: "compreensivo" ( $n=619$; OME = 2.27); "respeitador" ( $n=485$; OME = 2.37); "líder" ( $n$ = 423; OME = 2.44); e "simpático" ( $n=224 ;$ OME = 2.45).

Os indivíduos que não exercem qualquer cargo de chefia apresentaram um núcleo central (OME < 2.70) composto por cinco termos evocados, com um ponto de corte de $n=100$ na frequência de evocação. As frequências oscilaram entre $n=172$ e $n=757$ : "compreensivo" ( $n=757$; OME $=2.31)$; "respeitador" ( $n$ = 641; OME = 2.38); "líder" ( $n=557 ;$ OME = 2.43); "simpático" ( $n=271 ;$ OME = 2.61); e "competente" ( $n=$ 172; OME = 2.69).

Por último, o núcleo central (OME < 2.70) dos indivíduos que ocupam um cargo de chefia constituiu-se, igualmente, por cinco termos (ponto de corte de $n=40$ na frequência de evocação). As frequências oscilaram entre $n=46$ e $n=168$ : "compreensivo" ( $n=168$; OME = 2.49); "líder" $(n=149$; OME = 2.43); "respeitador" ( $n=140 ; \mathrm{OME}=2.53)$; "competente" $(n=55 ; \mathrm{OME}=2.49)$; e "simpático" $(n=$ 46 ; OME = 2.59).

\section{DISCUSSÃO}

As evocações livres sugerem que os elementos centrais da representação sobre o Chefe Ideal se organizam no sentido de o considerar como um chefe compreensivo, respeitador, simpático, líder e competente. Como podemos verificar, os resultados assinalam uma forte consistência no que concerne ao núcleo central da amostra global e em função das categorias definidas com base nas variáveis sociodemográficas. É importante começar por mencionar a palavra líder. No contexto dos dados recolhidos, esta palavra reporta-se a um significado que não é o atribuído pelos autores dos modelos que apresentámos. Em todos estes modelos os autores utilizam uma palavras que adicionam a liderança: servidora, ética, autêntica e empoderadora, respetivamente. Isto significa, portanto, que a palavra liderança por si só não acarreta o atributo que a segunda palavra lhe traz. Ou seja, nas respetivas conceções, a liderança pode ser não ética, não servidora, não autêntica e não empoderadora, requerendo o uso do qualificativo para que assuma as correspondentes características. Os nossos participantes, ao definirem o chefe ideal como líder, estão a atribuir certamente à palavra líder um conjunto de atributos adicionais que poderão estar contidos, pelo menos parcialmente, nos modelos de liderança virtuosa e positiva. Assim, permanece legítima a utilização daqueles modelos como termo de comparação com os nossos resultados.

Ao procurar verificar a proximidade semântica (isto é, quanto ao significado) entre os elementos do núcleo central e as dimensões dos modelos de liderança virtuosa e positiva que apresentámos previamente, constatamos que existe uma elevada proximidade, com escassos elementos descompassados. A Tabela 2 apresenta uma interpretação desta proximidade, em que associamos cada dimensão de liderança aos elementos do núcleo central da representação social que mais dela se aproximam.

Como podemos verificar, a categorização prototípica inclui no seu núcleo central componentes que parecem ser semanticamente próximos de dimensões de todos os modelos de liderança que analisámos. A liderança empoderadora (Amundsen \& Martinsen, 2014), na nossa interpretação, é a que se encontra mais representada em termos de proximidade semântica. Em cada um dos restantes modelos (Brown \& Treviño, 2006; Brown et al., 2005; Spears, 2010; Treviño et al., 2000; Walumbwa et al., 2008), uma ou duas dimensões ficam excluídas da correspondência. Por outro lado, todos os componentes da representação social do chefe ideal obtida no núcleo central parecem estar de alguma maneira presentes nos modelos de liderança referidos, mas estes constituem visões diferenciadas, complexas e singulares do que pode ser prescrito enquanto boa liderança. Estes modelos, tendo alguma proximidade do que a nossa amostra definiu como o chefe ideal, oferecem configurações singulares que se distinguem entre si e se organizam diferenciadamente em relação à representação social do chefe ideal obtida com a nossa amostra. Três diferenciações merecem ser salientadas: a) o chefe ideal tem mais componentes diretamente relacionados com a qualidade da relação e interação que só remotamente se associam às dimensões das lideranças analisadas; b) os modelos de liderança discutidos têm mais componentes diretamente associados a aspetos éticos; c) os componentes quer da representação social quer dos modelos de liderança encontram-se organizados de forma própria em cada uma das configurações, não se 
repetindo. Assim, nem a representação social, nem os modelos de liderança são redundantes uns em relação aos outros, salientando em cada caso aspetos específicos que se tornam figura, em detrimento dos demais que se constituem como fundo. No seu conjunto, parecem ser complementares. Deve, porém, ser mencionada a menor presença de componentes claramente éticos nos elementos do núcleo central. Embora elementos como o respeito integrem uma certa conotação ética, não existe uma afirmação clara e inequívoca deste componente. Este aspeto tem especial relevância se considerarmos que os dados foram recolhidos num momento histórico em que se noticiam frequentemente escândalos de corrupção e falta de ética de dirigentes políticos e organizacionais. Uma possível explicação para este facto decorre da eventual particularidade na significação de 'chefe'. Efetivamente, esta palavra poderá associar-se mais ao dirigente que lida na interação quotidiana com o trabalhador, conforme pretendíamos, e menos aos altos quadros da política e do mundo corporativo.

Tabela 2. Dimensões das lideranças autêntica, ética, servidora e empoderadora e respetiva proximidade com os elementos do núcleo central das representações sociais da amostra

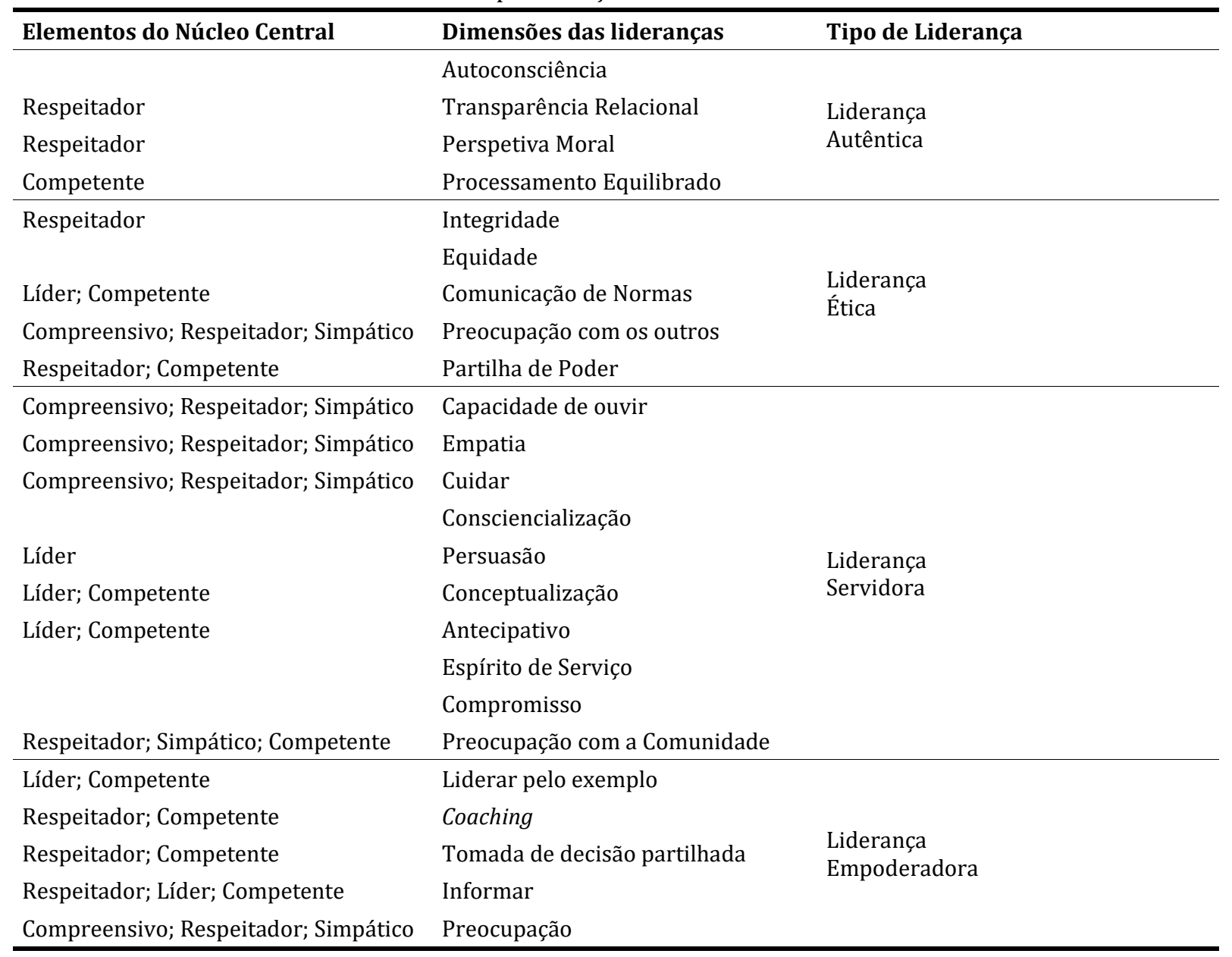

Esta possível explicação é reforçada pela centralidade predominante da pessoa e não da tarefa no núcleo central da representação social. Isto é, os termos evocados referem-se ao chefe enquanto agente de uma relação, cujos traços pessoais estão diretamente ligados à qualidade das relações e interações humanas que estabelece. Esta questão é relevante já que o estudo da eficácia da liderança tradicionalmente considerou medidas ligadas à tarefa e medidas ligadas às dimensões sociais da interação. Vemos assim que na representação do que é o chefe ideal predominam atributos que reforçam o seu papel enquanto agente de relação social (associados ao fator identificado como consideração), e não atributos que remetam para a organização e realização das tarefas inerentes ao trabalho a realizar (associados ao fator identificado como estruturação).

Embora nas periferias surjam evocações como "gestor", "delegar", "coordenador", "tomada de decisão", "pagamentos em dia", "foco nos objetivos", "pagar bem”, "capacidade crítica”, "gestão de conflitos", "resolve problemas", relacionadas com o fator tarefa e com a organização do trabalho, a 
verdade é que a grande maioria dos componentes das periferias é constituída por termos que realçam também o fator consideração, o que confirma a sua transversalidade ao longo dos quatro quadrantes.

Esta valorização das dimensões humanas na liderança (enquanto exercício de um cargo de chefia) parece ser corroborada por estudos prévios em Portugal (Portugal Ferreira, Aua Mané, \& Ribeiro Almeida, 2017; Rašković \& Kržišnik, 2010). A possibilidade de os nossos resultados serem, neste aspeto, principalmente a expressão de uma característica cultural, não deve ser descartada e estudos comparativos futuros poderão testar esta hipótese. Duas hipóteses adicionais parecem ainda plausíveis para explicar o predomínio das dimensões relacionais sobre as orientadas para as tarefas e objetivos: (1) a primeira possibilidade é a da maior acessibilidade do léxico das relações interpessoais que pode determinar que as respostas mais imediatas dos participantes sejam relativas a essa esfera da vida; (2) a segunda possibilidade, que não exclui a primeira, é que a impreparação das chefias em Portugal seja predominantemente ligada às competências de relacionamento, de índole comportamental, o que leva a que os indivíduos enfatizem no chefe ideal aquilo que não têm ou não presenciam na sua realidade quotidiana. Contribuiria para esclarecer esta hipótese um futuro estudo da relação entre 'chefe ideal' e o 'chefe real' com que o indivíduo interage diretamente no seu quotidiano. Estudos futuros poderão verificar o poder explicativo de cada uma das quatro hipóteses: se a da significação de 'chefe' como aquele com quem o trabalhador se relaciona quotidianamente, se a da maior acessibilidade do léxico relacional, se a da maior saliência de lacunas de competências relacionais nos dirigentes portugueses, ou ainda a da eventual característica cultural.

Quanto ao termo "não-existe", evocado no núcleo contrastante, é de destacar a sua singularidade. Ainda que referido por uma minoria, a expressão supradita foi umas das suas primeiras evocações, o que nos leva a refletir sobre a sua presença. Esta descrença na existência de um chefe capaz de corresponder às expectativas e à idealização dos liderados remete-nos para a dimensão afetiva que Seligman (1975) apelidou de learned helplessness ou desânimo aprendido. 0 desânimo aprendido é uma aprendizagem individual. Quando o indivíduo experiencia acontecimentos negativos que ocorrem independentemente das suas próprias ações ou se envolve em situações incontroláveis, aprende que os acontecimentos não dependem das suas respostas, caindo no desânimo e pessimismo (Seligman, 1975).

Posto isto, os subordinados, apercebendo-se da sua impotência relativamente à mudança de postura do seu líder, poderão adotar uma atitude derrotista e suspender novas tentativas, assumindo a sua passividade. Por outras palavras, os liderados, com base nas suas experiências negativas, poderão desenvolver expectativas de que no futuro nada mudará e, por conseguinte, aquando da confrontação do que para si seria o chefe ideal, terão possivelmente dado uma resposta perentória afirmando a sua inexistência.

A comparação do núcleo central da representação por sexo indica-nos que o termo "competente" emergiu exclusivamente em respondentes do sexo feminino da nossa amostra, apontando para uma valorização da competência no desempenho de cargos de chefia. Um chefe ideal é representado igualmente por homens e mulheres como sendo compreensivo, respeitador, líder e simpático, embora a competência seja um atributo exclusivo da representação social de chefe ideal feita pelo sexo feminino. Este resultado encontra-se em consonância com a literatura que indica um esforço acrescido por parte da mulher no alcance de uma posição de chefia em Portugal (Ferreira, 2010). 0 facto de se sentirem eventualmente preteridas no acesso a posições de chefia por discriminação sexual, poderá realçar a eventual baixa competência dos seus colegas masculinos que, entretanto, ocuparam tais posições. Acresce que “(...) tradicionalmente, atribuem-se ao homem papéis e responsabilidades no domínio público, de sustento, e de orientação para resultados, de competitividade e força, e à mulher papéis no domínio privado, de cuidado, com base em características mais emocionais e relacionais" (Rato, 2007, p. 8), parecendo legitimar, a priori, o desempenho de uma posição de chefia por parte dos homens e exigindo à mulher um esforço acrescido para o desempenho de tais cargos, onde a competência assume um elemento justificativo essencial.

Quanto à influência das gerações na representação social, há que atender a aspetos históricos, sociais, políticos e culturais da nossa sociedade que foram progressivamente moldando gerações e, provavelmente, contribuindo para uma representação social semelhante ou distinta daquilo que é um chefe ideal. Assim, se para a Silent Generation (cidadãos nascidos entre 1928 e 1945) um chefe ideal é fundamentalmente compreensivo e respeitador, as gerações seguintes passaram a valorizar mais os aspetos relacionados com a liderança, a competência e a simpatia, apesar de manterem os atributos relacionados com o respeito e a compreensão. Parece assim, que, nas gerações mais jovens, a representação social do que é um chefe ideal é mais rica e exigente. A noção de líder emerge logo na geração Baby Boomer (nascidos entre 1946 e 1964), mantendo-se até à geração mais recente analisada neste artigo (Millennials, nascidos entre 1981 e 2001). 0 mesmo percurso verifica-se com o atributo "competente", evidenciando a noção que o trabalhador possui de que um chefe ideal deve claramente 
traçar linhas de orientação e de trabalho com vista ao alcance de metas, de forma eficaz e eficiente. Assim, um chefe ou líder ideal terá de ser necessariamente competente, para além de ser simpático, respeitador e compreensivo. Estes últimos atributos alinham-se com os padrões éticos e morais que devem nortear o comportamento daqueles que desempenham funções de chefia. Os termos "respeitador" e "compreensivo", pertencentes ao núcleo central da representação social, aludem à flexibilidade e à tolerância desejadas para um chefe. Estes atributos são igualmente reconhecidos como ideais nos respondentes que ocupam um cargo de chefia, que indicaram como centrais, precisamente os mesmos termos que os trabalhadores que não ocupam cargos de chefia (ou seja, o chefe ideal como compreensivo, líder, respeitador, competente e simpático). Assim, o desempenho de cargos de chefia não alterou o núcleo central da representação social de como é um chefe ideal.

Embora a descrição das diferenças geracionais pareça plausível, não é despicienda a possibilidade de essas diferenças se deverem ao diferente momento do ciclo de vida em que os indivíduos de cada geração se encontravam no momento da recolha de dados. É de considerar a possibilidade de os indivíduos serem particularmente atentos a diferentes componentes da ideia de chefe ideal ao longo do ciclo de vida. Assim, os diferentes resultados encontrados em cada geração poderão expressar mais a idade aquando da coleta de dados do que as características da sua geração de pertença. Estudos futuros poderão contribuir para o esclarecimento desta questão.

\section{Implicações práticas e propostas de investigação futura}

A análise da similitude e das diferenças em relação ao núcleo central da representação social do Chefe Ideal em termos de sexo e classificação das gerações permite-nos levantar pistas para o modo como os diferentes entendimentos sobre o que é um chefe ideal podem influenciar a relação entre líder e subordinado, bem como a motivação e o engajamento dos colaboradores no trabalho. Assim, as organizações em geral, e as suas chefias em particular, devem estar atentas às diferenças que emergem decorrentes dos seus colaboradores pertencerem a diferentes sexos e gerações, bem como daquelas que resultam da pertença a períodos de transição de gerações, visto que carregam aspetos cognitivos, emocionais e comportamentais próximos das duas gerações em que transitam.

Em estudos futuros será interessante analisar em maior profundidade o núcleo contrastante da representação social do Chefe Ideal, no sentido de averiguar o que representa este pequeno segmento da amostra em termos populacionais e quais as características, contextos e situações de vida dessas pessoas, visto que com a presente investigação, neste quadrante da representação social, foi possível apreender uma predominância da dimensão pessoal (singular e individual) em detrimento de uma dimensão mais organizacional que engloba questões relativas à estrutura social e corporativa que permite a atuação de um chefe ou líder. Será igualmente interessante explorar a estrutura das representações sociais antes e após programas de formação em liderança. Desta forma, poderíamos avaliar a eficácia deste tipo de programas e os ganhos gerados ao nível da organização, das suas equipas de trabalho e dos seus colaboradores.

Será relevante testar as quatro hipóteses formuladas na discussão dos resultados sobre a menor presença de componentes primariamente éticos no núcleo central, e sobre o predomínio de componentes que realçam a visão do chefe enquanto agente relacional. Finalmente, será também clarificador estudar futuramente a variação da representação social ao longo da vida dos indivíduos, conforme referimos na discussão dos resultados. Esse estudo permitirá verificar em que medida as diferenças geracionais encontradas se devem ao diferente momento no ciclo de vida em que os dados foram coletados em cada geração, ou a reais diferenças intergeracionais.

\section{CONCLUSÃO}

A presente investigação visava caracterizar as representações sociais do chefe ideal. Verificámos que a categorização prototípica reflete a valorização do fator consideração, isto é, das relações e interações humanas, medidas através dos traços pessoais. Concluímos, também, que os elementos do núcleo central são semanticamente próximos de algumas das dimensões de todos os modelos de liderança virtuosa e positiva que analisámos, apesar de se encontrarem menos presentes componentes explicitamente éticos conforme representado nos modelos de liderança.

Independentemente das perspetivas e leituras aqui discutidas, graças ao manancial de evocações que obtivemos e à considerável dimensão da amostra, os dados que recolhemos atestam a importância de se continuar a estudar a liderança e as suas representações sociais. Por último, é necessário sublinhar as limitações deste estudo, particularmente a utilização do termo "chefe" em detrimento do termo "líder". Ainda que conscientes da conotação específica e tendencialmente associada ao exercício de um cargo de poder que pode ter influenciado os resultados, foi nossa decisão optar pelo termo "chefe", admitindo que é aquele que mais amplamente se associa ao exercício de um cargo em que existe hierarquia. Esta decisão 
foi profundamente enraizada na crença de que assim usaríamos uma expressão com a qual os participantes das diferentes gerações estão familiarizados, apesar de esta escolha poder ter encaminhado as respostas para a referência ao dirigente que diariamente lida com o trabalhador.

\section{REFERÊNCIAS}

Abric, J. C. (1976) Jeux, conflits et représentations sociales. Aix-en-Provence. Thèse d'État: Université de Provence.

Abric, J. C. (1987). Coopération, competition et représentations sociales. Cousse DelVal.

Abric, J. C. (1993). Central system, peripheral system: Their functions and roles in the dynamics of social representations. Papers on Social Representations, 2(2), 75-78.

Abric, J. C. (1994a). Pratiques sociales et représentations. Paris: PUF.

Abric, J. C. (1994b). L'organisation interne des representations sociales: Système central et système périphérique. In C. Guimelli (Org.), Structures et transformations des Representations Sociales (pp. 73-84). Neuchâtel: Delachaux et Niestlé.

Abric, J. C. (2001). L'approche structurale des représentations sociales: Développements récents. Psychologie et société, 4, 81-106.

Abric, J. C. (2003). La recherche du noyau central et de la zone muette des représentations sociales. In J. C. Abric (Ed.), Méthodes d'étude des représentations sociales (pp. 59-80). Ramonville Sant-Agne, France: Érès.

Aij, K. H., \& Rapsaniotis, S. (2017). Leadership requirements for lean versus servant leadership in health care: A systematic review of the literature. Journal of Healthcare Leadership, 9, 1-14. http://dx.doi.org/10.2147/jhl.s120166.

Almeida, S., \& Faro, A. (2016). Tradução, adaptação e validação do Servant Leadership Questionnaire (Escala de Liderança Servidora). Revista Psicologia: Organizações e Trabalho,16(3), 285-297. http://dx.doi.org/10.17652/rpot/2016.3.11929.

Amundsen, S., \& Martinsen, $\varnothing$ L. (2014). Empowering leadership: Construct clarification, conceptualization, and validation of a new scale. The Leadership Quarterly, 25(3), 487-511. http://dx.doi.org/10.1016/j.leaqua.2013.11.009.

Arnold, J., Arad, S., Rhoades, J., \& Drasgow, F. (2000). The empowering leadership questionnaire: The construction and validation of a new scale for measuring leader behaviors. Journal of Organizational Behavior, 21, 249-261.

Avolio, B. J., \& Gardner, W. L. (2005). Authentic leadership development: Getting to the root of positive forms of leadership. The Leadership Quarterly, 16(3), 315-338. http://dx.doi.org/10.1016/j.leaqua.2005.03.001

Bandura, A. (1977). Social learning theory. Englewood CliVs, NJ: Prentice-Hall.

Bandura, A. (1986). Social foundations of thought and action: A social cognitive theory. Englewood Cliffs, NJ: Prenctice Hall.

Bedi, A., Alpaslan, C. M., \& Green, S. (2016). A meta-analytic review of ethical leadership outcomes and moderators. Journal of Business Ethics, 139(3), 517-536. http://dx.doi.org/10.1007/s10551-0152625-1.

Besen, F., Tecchio, E., \& Fialho, F. (2017). Liderança autêntica e a gestão do conhecimento. Gestão \& Produção, 24(1), 2-14. http://dx.doi.org/10.1590/0104-530X898-13.

Blau, P. M. (1964). Exchange and power in social life. New York: Wiley.

Brown, M. E., Treviño, L. K., \& Harrison, D. A. (2005). Ethical leadership: A social learning perspective for construct development and testing. Organizational Behavior and Human Decision Processes, 97(2), 117-134. http://dx.doi.org/10.1016/j.obhdp.2005.03.002.

Brown, M., \& Treviño, L. K. (2006). Ethical leadership: A review and future directions. The Leadership Quarterly, 17(6), 595-616. http://dx.doi.org/10.1016/j.leaqua.2006.10.004.

Copeland, M. (2014). The emerging significance of values based leadership: A literature review. International Journal of Leadership Studies, 8(2), 105-135.

Daniel, F., Caetano, E., Monteiro, R., \& Amaral, I. (2016). Representações sociais do envelhecimento ativo num olhar genderizado. Análise Psicológica, 34(4), 353-364. http://dx.doi.org/10.14417/ap.1020.

Dany, L., Urdapilleta, I., \& Monaco, G. L. (2014). Free associations and social representations: Some reflections on rank-frequency and importance-frequency methods. Quality \& Quantity, 49(2), 489507. http://dx.doi.org/10.1007/s11135-014-0005-z.

Ferreira, V. (2010). A Igualdade de mulheres e homens no trabalho e no emprego em Portugal: Políticas e circunstâncias. Lisboa: CITE - Comissão para a Igualdade no Trabalho e no Emprego.

Finley, S. (2012). Servant leadership: A literature review. Review of Management Innovation \& Creativity, 5(14), 135-144. 
Flynn, G. (2010). Leadership and business ethics (Vol. 25). Dordrecht: Springer.

Gardner, W. L., Avolio, B. J., Luthans, F., May, D. R., \& Walumbwa, F. O. (2005). Can you see the real me? A self-based model of authentic leader and follower development. The Leadership Quarterly, 16, 34372. http://dx.doi.org/10.1016/j.leaqua.2005.03.003.

Greenleaf, R. K. (1970). The servant as leader. Indianapolis: The Robert K. Greenleaf Center.

Harter, S. (2002). Authenticity. In C. S. Snyder, \& S. J. Lopez (Eds.), Handbook of positive psychology (pp. 382 - 394). Oxford: Oxford University Press.

Holtz, B. C., \& Harold, C. M. (2012). Effects of leadership consideration and structure on employee perceptions of justice and counterproductive work behavior. Journal of Organizational Behavior, 34(4), 492-519. http://dx.doi.org/10.1002/job.1825.

Hsiung, H. (2012). Authentic leadership and employee voice behavior: A multi-level psychological process. Journal of Business Ethics, 107(3), 349-361. http://dx.doi.org/10.1007/s10551-01110432.

Hunter, E. M., Neubert, M. J., Perry, S. J., Witt, L., Penney, L. M., \& Weinberger, E. (2013). Servant leaders inspire servant followers: Antecedents and outcomes for employees and the organization. The Leadership Quarterly, 24(2), 316-331. http://dx.doi.org/10.1016/j.leaqua.2012.12.001.

Judge, T. A., Piccolo, R. F., \& Ilies, R. (2004). The forgotten ones? The validity of consideration and initiating structure in leadership research.Journal of Applied Psychology, 89(1), 36-51. http://dx.doi.org/10.1037/0021-9010.89.1.36.

Lorinkova, N. M., Pearsall, M. J., \& Sims, H. P. (2013). Examining the differential longitudinal performance of directive versus empowering leadership in teams. Academy of Management Journal, 56(2), 573596. http://dx.doi.org/10.5465/amj.2011.0132

Manz, C. C., \& Sims, H. P. (1980). Self-Management as a substitute for leadership: A social learning theory perspective. The Academy of Management Review, 5(3), 361-367. http://dx.doi.org/10.2307/257111.

Miniotaitè, A., \& Bučiūnienè, I. (2013). Explaining authentic leadership work outcomes from the perspective of self-determination theory. Management of Organizations: Systematic Research, 65, 63-75. http://dx.doi.org/10.7220/mosr.1392.1142.2013.65.5.

Miska, C. c., \& Mendenhall, M. M. (2018). Responsible leadership: A mapping of extant research and future directions. Journal of Business Ethics, 148(1), 117-134. http://dx.doi.org/10.1007/s10551-0152999-0

Moriano, J., Molero, F., \& Mangin, J. (2011). Liderazgo auténtico: Concepto y validación del cuestionario ALQ en España. Psicothema, 23(2), 336-341.

Moscivici, S. (1981). A representação social da psicanálise. Rio de Janeiro: Zahar.

Mubasher, U., Salman, Y., Irfan, S., \& Jabeen, N. (2017). Spiritual leadership in organizational context: A research gap in South Asia. South Asian Studies (1026-678X), 32(1), 205-218.

Neves, M., Jordão, F., Cunha, M., Vieira, D., \& Coimbra, J. (2016). Estudo de adaptação e validação de uma escala de perceção de liderança ética para líderes portugueses. Análise Psicológica, 2(34), 165-176. http://dx.doi.org/10.14417/ap.1028

Newman, A., Schwarz, G., Cooper, B., \& Sendjaya, S. (2015). How servant leadership influences organizational citizenship behavior: The roles of LMX, empowerment, and proactive personality. Journal of Business Ethics, 145(1), 49-62. http://dx.doi.org/10.1007/s10551-0152827-6.

Oliveira, D. C., Marques, S. C., Gomes, A. M. T., Teixeira, M. C. T. V., \& Amaral, M. A. D. (2005). Análise das evocações livres: Uma técnica de análise estrutural das representações sociais. In A. S. Paredes (Org.). Perspectivas teórico-metodológicas em representações sociais (pp. 573-603). João Pessoa: Editora Universitária UFPB.

Parris, D., \& Peachey, J. (2013). A systematic literature review of servant leadership theory in organizational contexts. Journal of Business Ethics, 113(3), 377-393. http://dx.doi.org/10.1007/s10551-012-1322-6.

Pearce, C. L., \& Sims, H. P. (2002). Vertical versus shared leadership as predictors of the effectiveness of change management teams: An examination of aversive, directive, transactional, transformational, and empowering leader behaviors. Group Dynamics: Theory, Research, and Practice, 6(2), 172-197. http://dx.doi.org/10.1037//1089-2699.6.2.172.

Peus, C., Wesche, J. S., Streicher, B., Braun, S., \& Frey, D. (2011). Authentic leadership: An empirical test of its antecedents, consequences, and mediating mechanisms. Journal of Business Ethics, 107(3), 331348. http://dx.doi.org/10.1007/s10551-011-1042-3.

Portugal Ferreira, M., Aua Mané, M., \& Ribeiro Almeida, M. (2017). Aplicação das dimensões culturais do projeto Globe na avaliação da liderança ética: Um estudo intercultural em Portugal e Guiné-Bissau. 
Brazilian Journal of Management, Revista de Administração da UFSM, 10(2), 245-264. http://dx.doi.org/10.5902/1983465912868

Randolph-Seng, B., \& Gardner, W. L. (2012). Validating measures of leader authenticity: Relationships between implicit/explicit self-esteem, situational cues, and leader authenticity. Journal of $\begin{array}{lllll}\text { Leadership } \quad \text { O } \quad \text { Studies, } & \text { 20(2), }\end{array}$ http://dx.doi.org/10.1177/1548051812464780.

Rašković, M., \& Kržišnik, Š. (2010). Cross-cultural comparison of leadership practices from Slovenia and Portugal using the Globe Research Program methodology. Portuguese Journal of Management Studies, 15(1), 13-33.

Rato, H. (Coord.). (2007). A igualdade de género na administração pública central portuguesa. Instituto Nacional de Administração. Fundação para a Ciência e Tecnologia.

Reed, L. L., Vidaver-Cohen, D., \& Colwell, S. R. (2011). A new scale to measure executive servant leadership: Development, analysis, and implications for research. Journal of Business Ethics, 101(3), 415-434. http://dx.doi.org/10.1007/s10551-010-0729-1.

Rosa, E., Tafani É., Michel, G., \& Abric, J. (2011). Rôle du processus de catégorisation dans le fonctionnement des représentations sociales: Une application dans le champ du marketing? Les cahiers internationaux de psychologie sociale, 91(3), http://dx.doi.org/10.3917/cips.091.0253.

Sá, C. P. (1996). Representações sociais: Teoria e pesquisa do núcleo central. Temas em Psicologia, (3), 1933.

Sá, C. P. (1998). Núcleo central das representações sociais. Petrópolis: Vozes.

Schwartz, A. J. (2015). Inspiring and equipping students to be ethical leaders. New Directions for Student Leadership, 2015(146), 5-16. http://dx.doi.org/10.1002/yd.20131.

Seligman, M. E. (1975). Helplessness: On depression, development, and death. New York, NY: Freeman.

Sharma, P. N., \& Kirkman, B. L. (2015). Leveraging leaders: A literature review and future lines of inquiry for empowering leadership research.Group \& Organization Management, 40(2), 193-237. http://dx.doi.org/10.1177/1059601115574906.

Spears, L. (2010). Character and servant leadership: Ten characteristics of effective, caring leaders. The Journal of Virtues \& Leadership, 1(1), 25-30. http://dx.doi.org/10.1.1.475.5814.

Suh, M. (2015). Definitions. Retrieved January 05, 2018, from http://www.pewresearch.org/methodology/demographic-research/definitions/

Treviño, L. K., Hartman, L. P., \& Brown, M. (2000). Moral person and moral manager: How executives develop a reputation for ethical leadership. California Management Review, 42(4), 128-142. http://dx.doi.org/10.2307/41166057.

Trochim, W. M., Donnelly, J. P., \& Arora, K. (2016). Research methods: The essential knowledge base. Boston, MA: Cengage Learning.

Vala, J., \& Castro, P. (2013). Pensamento social e representações sociais. In J. Vala \& M. B. Monteiro (Eds.), Psicologia social (9th ed., pp. 569-602). Lisboa: Fundação Calouste Gulbenkian.

Vergès P. (2002). Conjunto de programas que permitem a análise de evocações: EVOC manual, Versão 5. Aix-en-Provence.

Walumbwa, F., Avolio, B., Gardner, W., Wernsing, T., \& Peterson, S. (2008). Authentic leadership: Development and validation of a theory-based measure. Journal of Management, 34(1), 89-126. http://dx.doi.org/10.1177/0149206307308913.

Wolde, A., Groenendaal, J., Helsloot, I., \& Schmidt, A. (2014). An explorative study on the connection between ethical leadership, prototypicality and organizational misbehavior in a dutch fire service. International Journal of Leadership Studies, 8(2),18-43.

\begin{tabular}{|c|c|}
\hline Historial a & tigo \\
\hline Recebido & $02 / 18$ \\
\hline Aceite & $05 / 19$ \\
\hline Publicado & $08 / 19$ \\
\hline
\end{tabular}

